\title{
The Role of Radiotracer Imaging in the
} Diagnosis and Management of Patients with Breast Cancer: Part 1-Overview, Detection, and Staging*

\author{
Jean H. Lee ${ }^{1}$, Eric L. Rosen ${ }^{2}$, and David A. Mankoff ${ }^{1}$ \\ ${ }^{I}$ Department of Radiology, Seattle Cancer Care Alliance and University of Washington, Seattle, Washington; and ${ }^{2}$ Seattle \\ Radiologists, Seattle, Washington
}

\begin{abstract}
Breast cancer is the most common non-skin type of cancer and the second leading cause of cancer mortality in women. Advances in diagnosis and treatment have led to declines in mortality, despite an increase in breast cancer incidence. An advancing array of both local and systemic therapy options has led to increasingly individualized treatment. Imaging plays a key role in detecting breast cancer and directing its therapy. This continuing education article, part 1 in a 2-part series, provides a comprehensive review of current and future radiotracer imaging methods applied to breast cancer, in the context of breast cancer management strategies and other nonnuclear imaging methods. Part 1 of the review provides an overview of clinical and biologic considerations in breast cancer and covers radionuclide imaging for detection and staging. Part 2 will cover radionuclide imaging of breast cancer response to therapy, other clinical indications for radionuclide breast cancer imaging, and future directions, including molecular imaging.
\end{abstract}

Key Words: breast cancer; oncology; PET; nuclear medicine

J Nucl Med 2009; 50:569-581

DOI: 10.2967/jnumed.108.053512

\section{B} reast cancer is the most common non-skin type of cancer and the second leading cause of cancer mortality in women (1). Although the incidence of breast cancer continues to rise, mortality has declined over the past several years $(1,2)$. The decline has been attributed to both early diagnosis and more effective treatment (2). Advances in

Received Sep. 6, 2008; revision accepted Dec. 23, 2008.

For correspondence or reprints contact: David A. Mankoff, Seattle Cancer Care Alliance Radiology, G2-600, 825 Eastlake Ave., East Seattle, WA 98109.

E-mail: dam@u.washington.edu

*NOTE: FOR CE CREDIT, YOU CAN ACCESS THIS ACTIVITY THROUGH THE SNM WEB SITE (http://www.snm.org/ce_online) THROUGH APRIL 2010.

David Mankoff has indicated he receives scientific study/trial support from Pfizer and GE Healthcare. No other potential conflict of interest relevant to this article was reported.

COPYRIGHT @ 2009 by the Society of Nuclear Medicine, Inc. molecular cancer biology have led to an increased understanding of the biologic factors that contribute to breast cancer pathogenesis and progression. This understanding has already led to new and effective treatments (3), and new targeted therapies continue to be developed and tested (4). Advances in breast cancer molecular biology have also yielded improvements in diagnosis through molecular pathology and molecular imaging $(5,6)$.

Radiotracer imaging studies have played, and will continue to play, an important role in breast cancer care. This continuing education article first reviews classification schemes for breast cancer pathology and staging and then gives an overview of approaches to breast cancer treatment to frame the diagnostic needs for breast cancer care and provide an outline of the categories of diagnostic tasks for which imaging plays a role. The discussion then reviews the application of radiotracer imaging methods to breast cancer diagnosis and treatment in the context of diagnostic needs and other nonradiotracer imaging methods. Part 1 provides an overview of clinical and biologic considerations in breast cancer and covers radionuclide imaging for detection and staging. Part 2 will cover radionuclide imaging of breast cancer response to therapy, other clinical indications for radionuclide breast cancer imaging, and future directions, including molecular imaging.

\section{INCIDENCE, RISK FACTORS, PATHOLOGY, AND CLASSIFICATION}

Breast cancer is largely a disease of women, with an annual incidence of 125 per 100,000 in the United States (1). The most well-established risk factors for breast cancer include age, family history and genetics, late first pregnancy, and obesity (7). Age is an important risk factor, and most of the women with breast cancer are postmenopausal; however, breast cancer is not uncommon in premenopausal women and often more aggressive in this group than in postmenopausal women. The recognition of gene mutations in the germ cell 
line (8)-for example, in the BRCA1 gene-was a major advance in understanding the basis of inherited disease, and a consideration of genetic profile is increasingly incorporated in breast cancer risk assessment, particularly for families prone to breast cancer at an early age.

Features of the pathologic classification of breast cancer are listed in Table 1. Breast cancers arise from the epithelial cells in the breast cancer ducts (9). The most important histologic feature in the primary tumor is the presence or absence of tumor invasion beyond the ductal architecture. Tumors that have not broken through the outer boundaries of ductal structures are termed noninvasive (ductal carcinoma in situ) and rarely metastasize (9), whereas invasive cancers have demonstrated their ability to break through tissue boundaries at the time of diagnosis and can metastasize both through lymphatic and hematologic spread. Other histologic features include the architectural pattern (ductal, lobular, or mixed) and the presence or absence of lymphovascular invasion (9). In addition to morphologic analyses, biopsy material is routinely assayed for phenotypic features that include the expression of hormone receptors (estrogen receptor [ER] and progesterone receptor $[\mathrm{PR}]$ ) and HER2/neu (also known as cerbB2), typically by immunohistochemistry or fluorescent in situ hybridization. These markers predict tumor aggressiveness and behavior, and are also targets for specific therapy (10).

The use of gene-expression profiling methods has yielded further insights into breast cancer phenotype (11). A common classification scheme centers on a model of ductal architecture. At the center of the ductal structure are cells that have the phenotype of ductal epithelial cells and are termed luminal. These cells most often express hormone receptors (ER and PR) and sometimes overexpress HER2 (typically luminal B). At the other extreme are those

\begin{tabular}{cc}
\hline $\begin{array}{c}\text { TABLE 1. Pathologic } \\
\text { Variable }\end{array}$ & \multicolumn{1}{c}{ Classification of Breast Cancer } \\
$\begin{array}{cc}\text { Tumor invasion and } \\
\text { appearance }\end{array}$ & $\begin{array}{c}\text { Noninvasive } \\
\text { DCIS } \\
\text { LCIS } \\
\text { Invasive } \\
\text { Invasive ductal carcinoma } \\
\text { Invasive lobular carcinoma } \\
\text { Other less common variants }\end{array}$ \\
& Histologic grade \\
Other histologic & Presence of lymphovascular invasion \\
assessments & Presence of microcalcifications \\
& Hormone receptor expression \\
Commonly measured & Estrogen receptor (ER) \\
phenotypic features & Progesterone receptor (PR) \\
& HER2/Neu expression \\
& (also known as cerbB2) \\
& Proliferation assay (e.g., Ki-67 index) \\
& \\
\hline DCIS = ductal carcinoma in situ; LCIS = lobular carcinoma in \\
situ.
\end{tabular}

cells that conceptually have features of the outer myoepithelial cell layer, termed basal cells. These cells most commonly lack expression of ER, PR, and HER2, often termed triple-negative cancers (12). The ability to measure gene expression has also increased the ability to predict tumor aggressiveness and the likelihood of recurrence, and some predictive expression panels are now approved and used in clinical practice (13).

Breast cancer stages are defined in Tables 2 and 3. The most widely accepted system is that of the American Joint Committee on Cancer, which uses a TNM approach (Table 2) (14). There is also a stage classification, which includes groups of TNM categories ranging from early-stage disease (stage I) to late-stage metastatic disease (stage IV) (Table 3). Improved diagnosis and staging, especially sentinel lymph node (SLN) mapping, has resulted in recent updates in the staging definitions (14).

TABLE 2. Summary of American Joint Committee on Cancer Staging System for Breast Cancer

\begin{tabular}{|c|c|}
\hline Category & Definition \\
\hline \multicolumn{2}{|l|}{ Tumor $(\mathrm{T})$} \\
\hline TO & No primary tumor found \\
\hline Tis & Carcinoma in situ \\
\hline T1 & Invasive cancer $<2 \mathrm{~cm}$ in greatest dimension \\
\hline T1mic & Microinvasion $\leq 0.1 \mathrm{~cm}$ in greatest dimension \\
\hline T1a & $\begin{array}{l}\text { Tumor }>0.1 \mathrm{~cm} \text { but } \leq 0.5 \mathrm{~cm} \text { in greatest } \\
\text { dimension }\end{array}$ \\
\hline T1b & $\begin{array}{l}\text { Tumor }>0.5 \mathrm{~cm} \text { but } \leq 1 \mathrm{~cm} \text { in greatest } \\
\text { dimension }\end{array}$ \\
\hline T1c & $\begin{array}{l}\text { Tumor }>1 \mathrm{~cm} \text { but } \leq 2 \mathrm{~cm} \text { in greatest } \\
\text { dimension }\end{array}$ \\
\hline T2 & $\begin{array}{l}\text { Tumor }>2 \mathrm{~cm} \text { but } \leq 5 \mathrm{~cm} \text { in greatest } \\
\text { dimension }\end{array}$ \\
\hline T3 & Tumor $>5 \mathrm{~cm}$ in greatest dimension \\
\hline T4 & $\begin{array}{l}\text { Tumor of any size with direct extension to } \\
\text { chest wall or skin }\end{array}$ \\
\hline \multicolumn{2}{|c|}{ Regional lymph nodes $(\mathrm{N})^{\star}$} \\
\hline NO & No regional nodal metastases \\
\hline N1 & Metastasis in mobile ipsilateral axillary nodes \\
\hline N2 & $\begin{array}{l}\text { Metastasis to fixed ipsilateral axillary nodes } \\
\text { (N2a) or ipsilateral IM nodes in absence of } \\
\text { ipsilateral axillary lymph node } \\
\text { metastasis (N2b) }\end{array}$ \\
\hline N3 & $\begin{array}{l}\text { Metastases in ipsilateral infraclavicular } \\
\text { nodes and axillary nodes (N3a) or ipsilateral } \\
\text { IM nodes and axillary nodes (N3b) or } \\
\text { metastases to ipsilateral supraclavicular } \\
\text { nodes (N3c) }\end{array}$ \\
\hline \multicolumn{2}{|c|}{ Distant metastases $(\mathrm{M})$} \\
\hline MO & No distant metastases \\
\hline M1 & Distant metastases \\
\hline
\end{tabular}

*This system is for clinical staging. Pathologic staging for nodal metastases is further classified for sentinel lymph nodes for detection based on immunohistochemical and molecular assays.

Table is adapted from Singletary and Connolly (14). 
TABLE 3. Alternative Staging System for Invasive

Breast Cancer

\begin{tabular}{ll} 
Stage & \multicolumn{1}{c}{ Category } \\
II & T1N0M0 \\
IIA & TON1M0 \\
& T1N1M0 \\
& T2NOM0 \\
IIB & T2N1M0 \\
III & T3NOM0 \\
IIIA & T3N1M0 \\
IIIB & T1-3N2M0 \\
IIIC & T4N0-2M0 \\
IV & Any T, N3M0 \\
\hline
\end{tabular}

\section{TREATMENT OPTIONS}

To understand diagnostic needs for breast cancer, it is important to understand the range of approaches to breast cancer treatment (Table 4). With the exception of early- and late-stage disease, almost all breast cancer care involves a

\section{TABLE 4. Current Treatment Options for Breast Cancer}

\begin{tabular}{|c|c|}
\hline Type of treatment & Example \\
\hline \multicolumn{2}{|l|}{ Locoregional } \\
\hline \multirow[t]{2}{*}{ Primary tumor resection } & Mastectomy \\
\hline & $\begin{array}{l}\text { Breast conservation surgery } \\
\text { ("lumpectomy") }\end{array}$ \\
\hline \multirow[t]{2}{*}{ Axillary nodal sampling } & Sentinel lymph node dissection \\
\hline & Axillary lymph node dissection \\
\hline \multirow{3}{*}{$\begin{array}{l}\text { Primary tumor } \\
\text { radiotherapy }\end{array}$} & Full breast irradiation \\
\hline & Partial breast irradiation \\
\hline & Brachytherapy \\
\hline \multirow[t]{3}{*}{ Regional radiotherapy } & Standard nodal field irradiation \\
\hline & $\begin{array}{l}\text { Conformal therapy of regional } \\
\text { nodes }\end{array}$ \\
\hline & Chest wall irradiation \\
\hline \multicolumn{2}{|l|}{ Systemic } \\
\hline Chemotherapy, adjuvant & Anthracyclines, taxanes, others \\
\hline $\begin{array}{l}\text { Chemotherapy, } \\
\text { metastatic }\end{array}$ & Anthracyclines, taxanes, others \\
\hline \multirow[t]{3}{*}{ Endocrine therapy } & $\begin{array}{l}\text { SERMs (selective estrogen } \\
\text { receptor modulators, } \\
\text { e.g., tamoxifen) }\end{array}$ \\
\hline & $\begin{array}{l}\text { Aromatase inhibitors (e.g., } \\
\text { letrozole) }\end{array}$ \\
\hline & $\begin{array}{l}\text { SERDs (selective estrogen } \\
\text { receptor demodulators, } \\
\text { e.g., fulvestrant) }\end{array}$ \\
\hline \multirow[t]{2}{*}{$\begin{array}{l}\text { Targeted (biologic) } \\
\text { therapy }\end{array}$} & $\begin{array}{l}\text { Anti-HER2 (e.g., trastuzumab, } \\
\text { lapatinib) }\end{array}$ \\
\hline & $\begin{array}{l}\text { Anti-angiogenesis (e.g., } \\
\text { bevacizumab) }\end{array}$ \\
\hline \multirow[t]{2}{*}{ Other } & $\begin{array}{l}\text { Inhibit bone resorption (e.g., } \\
\text { bisphosphonates) }\end{array}$ \\
\hline & $\begin{array}{l}\text { Bone marrow support (e.g., } \\
\text { filgastrim [granulocyte } \\
\text { colony-stimulating factor]) }\end{array}$ \\
\hline
\end{tabular}

combination of locoregional and systemic treatments. Locoregional therapy includes surgery and radiotherapy, and systemic therapy includes chemotherapy (e.g., taxanes), endocrine therapy (hormonal, e.g., aromatase inhibitors), and targeted therapy (biologic, e.g., anti-HER2 drugs).

Surgical excision of the primary tumor remains a key feature of the treatment of newly diagnosed breast cancer (15) and can be accomplished by mastectomy, removal of the entire breast, or by breast-conserving surgery, often termed lumpectomy of cancer (15). When lumpectomy is accompanied by postsurgical radiotherapy, breast conservation provides acceptably low rates of local recurrence and similar survival but with preservation of the breast (16). Recent advances in primary breast surgery include oncoplastic methods and improvements in reconstructive surgery to preserve, as much as possible, cosmetic integrity for breast cancer patients (17). For invasive disease, axillary nodal staging is routinely performed at the time of surgery. Approaches include targeted SLN dissection, guided by mapping techniques, and full axillary nodal dissection, guided by anatomic boundaries (18). Axillary sampling is performed largely for diagnostic purposes; the therapeutic value of lymph node removal remains largely unproven (19).

Radiotherapy is commonly used as an adjunct to surgery in locoregional breast cancer treatment (20). Breast radiotherapy is a key component of breast-conservation therapy, and for most tumors, lumpectomy performed without breast radiotherapy leads to unacceptably high rates of local recurrence (16). Therefore, breast radiotherapy is considered an integral part of breast-conservation treatment. Breast radiotherapy has traditionally been performed by fractionated whole-breast irradiation; however, interest in partial-breast irradiation and brachytherapy methods, especially for smaller tumors, has increased (21). Adjuvant chest wall irradiation can also be used in mastectomy patients and is usually reserved for patients with larger tumors or documented chest wall invasion (20). Adjuvant radiotherapy is also used in the treatment of regional nodal basins and has been shown to enhance survival in those patients with multiple axillary nodal metastases (22). Ongoing studies are examining the value of adjuvant radiotherapy in patients with more limited axillary nodal disease. Finally, palliative radiotherapy can be effective in selective treatment of breast cancer metastases to control symptoms or preserve structural integrity in the case of bone metastases.

Among solid tumors, breast cancer is one of the cancers most amenable to systemic therapy, in the form of both cytotoxic chemotherapy and more targeted treatments. One of the significant advances in breast cancer treatment was the recognition that breast cancer is a systemic disease and that even early breast cancer, with apparently limited extent, can give rise to micrometastases, leading to recurrence after apparently complete excision (16). To address this problem, adjuvant systemic therapy is used in addition to locoregional therapy in most invasive cancers and is credited, in part, for a reduction in breast cancer mortality. 
Systemic cytotoxic chemotherapy is used commonly in more advanced or aggressive tumors, particularly in those that lack ER or PR expression (23). In ER-expressing tumors, adjuvant endocrine therapy is used, typically an aromatase inhibitor or tamoxifen (24). In higher-risk ERexpressing tumors, both chemotherapy and endocrine therapy can be used (23). Both types of treatment are primary therapy for metastatic disease (25). In addition to chemotherapy and endocrine therapy, there is an increasing array of other targeted systemic treatments for breast cancer. Most notable is the development of treatments for patients whose tumors overexpress HER2. These agents (trastuzumab and, more recently, lapatinib) have become key components of both adjuvant and metastatic systemic therapy $(3,26)$. The antiangiogenesis drug bevacizumab was also recently approved for metastatic breast cancer (27). New breast cancer targets continue to be investigated (4) and may be especially important in triple-negative patients (ER/PR/ HER2-negative), in whom endocrine and HER2-targeted therapies are unlikely to work (28).

The choice of therapeutic approach depends on the disease burden at presentation, the likelihood of additional spread or progression, patient comorbidities, and patient preference. For noninvasive cancers, local therapy (surgery and radiotherapy) is sufficient. Some studies have suggested that endocrine therapy may reduce the incidence of local recurrence and new primary tumors. For nonmetastatic cancers with invasive disease (other than stage IV and not including those patients with small tumors $<1 \mathrm{~cm}$, which may be treated by local therapy alone in some cases), treatment is typically surgical excision with or without radiotherapy, followed by adjuvant systemic therapy (29). For patients with a larger local disease burden, particularly those with locally advanced breast cancer (LABC; large primary tumor or advanced axillary disease without clinically apparent distant metastases), systemic therapy may be administered in advance of local therapy, often termed neoadjuvant therapy (30). Because breast cancer that is metastatic beyond the regional node (stage IV) is rarely cured, systemic therapy is the primary treatment for metastatic disease, with locoregional treatment reserved for symptom control and used possibly in some patients with limited metastatic disease who may achieve prolonged remissions (25).

\section{DIAGNOSTIC TASKS FOR BREAST CANCER}

The diagnostic tasks for breast cancer are summarized in Table 5. For each task, the commonly used methods are listed, with the selected approaches that are either less commonly used or still undergoing clinical testing indicated by parentheses. Perhaps the most important diagnostic task is breast cancer detection. Breast cancers can be discovered by physical examination by the patient or her physician (symptomatic patients) or found by imaging performed for screening in asymptomatic patients. For imaging, the word

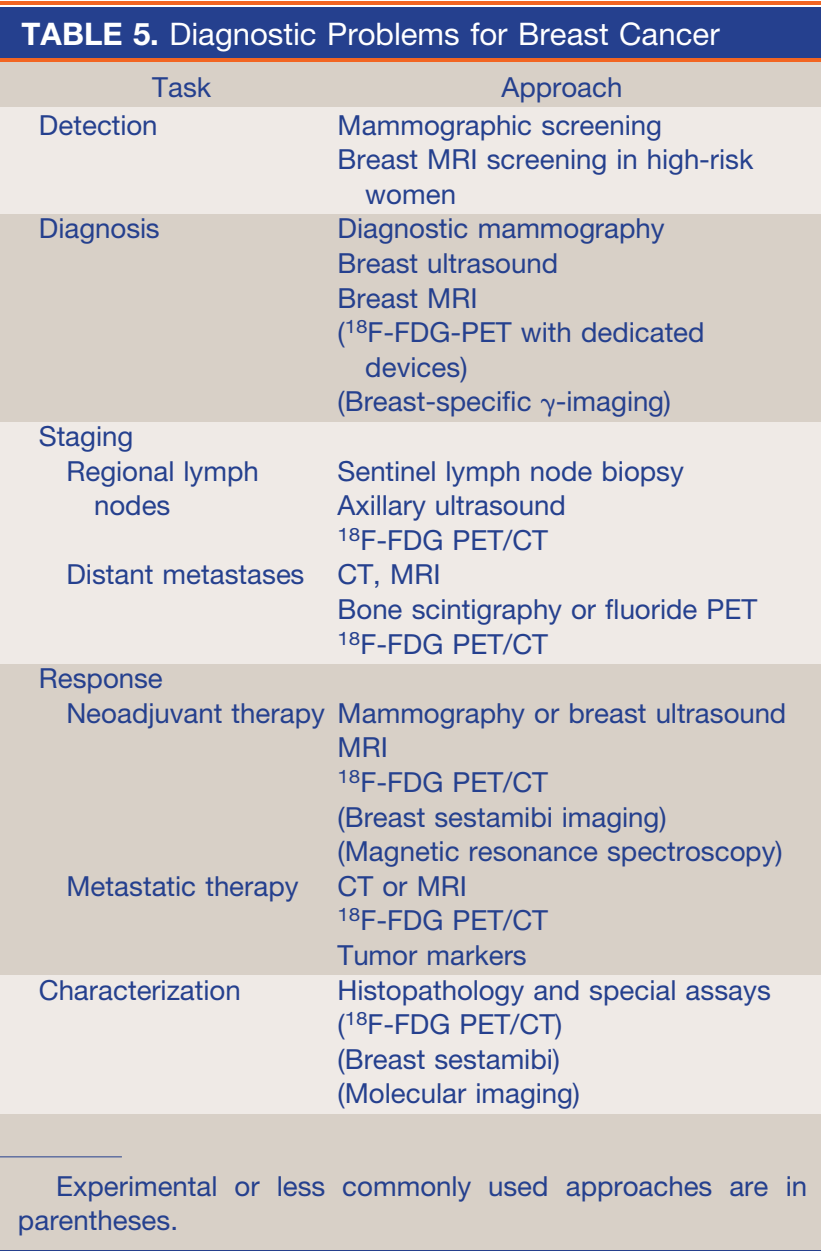

detection is usually used in conjunction with breast cancer screening, most commonly performed using mammography. Breast cancer diagnosis involves the characterization of a suspected mass or imaging finding and entails tissue sampling to make a definitive diagnosis of cancer versus benign disease. Staging is the determination of the extent of the disease burden in a patient with a known or highly suspected cancer, including the extent of disease in the affected breasts, regional lymph nodes, and distant (systemic) sites. We combine the discussion of breast cancer detection, diagnosis, and staging into a discussion of primary tumor imaging. For patients undergoing systemic therapy in the neoadjuvant or metastatic setting, measuring therapeutic response, which involves some form of imaging in almost all cases, is important. Finally, we include the category of disease characterization, namely measuring the specific biologic characteristics of the tumor to predict its likely behavior, including response to treatment. Although this task has thus far been confined to assays of biopsy material (i.e., nonimaging approaches), we briefly highlight how emerging imaging methods may also play a role in characterizing breast cancer and helping to direct treatment. 


\section{DETECTION AND DIAGNOSIS}

\section{Overview}

Most primary cancers are detected by physical examination or mammography during screening or clinical workup of a breast lesion (31). Mammography is the primary imaging modality for breast cancer screening, detection, and diagnosis (32). Although mammography is an effective imaging tool, its limitations include moderate sensitivity and specificity (32); therefore, many other imaging modalities have been investigated to complement and increase the diagnostic accuracy of breast imaging. Ultrasound and MRI are important adjuncts to mammography for both diagnosis and characterization of breast cancer and are routinely used in this role $(33,34)$. Ease of use and real-time imaging capability make breast ultrasound one of the methods of choice for guiding breast biopsies and other interventional procedures (35). Breast MRI is rapidly emerging as an important clinical tool, especially for determining extent of disease within the breast, and can also be used to direct biopsy (34). In addition, MRI has shown utility for screening in high-risk women and was recently incorporated into the American Cancer Society recommendations for screening of high-risk patients (36).

\section{PET and Positron Emission Mammography (PEM)}

The finding of increased ${ }^{18} \mathrm{~F}-\mathrm{FDG}$ uptake in cancer spurred interest in the use of ${ }^{18} \mathrm{~F}-\mathrm{FDG}$ to diagnose primary breast cancers. Most studies have suggested that the degree of ${ }^{18}$ F-FDG uptake is somewhat correlated with breast cancer phenotype such as histologic type (higher uptake in ductal vs. lobular cancers), tumor histologic grade, and indices of cellular proliferation (higher uptake with higher levels of proliferation) $(37,38)$. Low uptake is seen in ductal carcinoma in situ and well-differentiated forms such as grade I lobular breast cancer (37).

Although whole-body ${ }^{18} \mathrm{~F}-\mathrm{FDG}$ PET has reasonable sensitivity and specificity in detecting malignant lesions in general, its sensitivity for primary breast cancer is limited. Overall, the sensitivity of ${ }^{18} \mathrm{~F}$-FDG PET in detecting primary breast cancer is $64 \%-96 \%$, specificity is $73 \%-100 \%$, positive predictive value is $81 \%-100 \%$, and negative predictive value is $52 \%-89 \%$ (31). Multiple investigators have demonstrated the diminished ability of ${ }^{18}$ F-FDG PET to detect a small, well-differentiated in situ breast carcinoma. Kumar et al. (39) evaluated ${ }^{18} \mathrm{~F}$-FDG PET of 85 primary breast cancers and demonstrated that tumor size less than $1 \mathrm{~cm}$ and low tumor grade were significant predictors of a false-negative ${ }^{18} \mathrm{~F}-\mathrm{FDG}$ PET results. Because primary breast cancer detection requires the ability to depict occult, nonpalpable, small $(<1 \mathrm{~cm})$ invasive and in situ malignant lesions, whole-body ${ }^{18} \mathrm{~F}-\mathrm{FDG}$ PET is not used in primary breast cancer detection.

To overcome the limitations of whole-body ${ }^{18} \mathrm{~F}-\mathrm{FDG}$ PET, dedicated breast PEM units have been developed (Fig. 1) (40). The advantages of PEM, compared with whole-body ${ }^{18} \mathrm{~F}$-FDG PET, include higher spatial resolution, shorter imaging time, and reduced attenuation; PEM
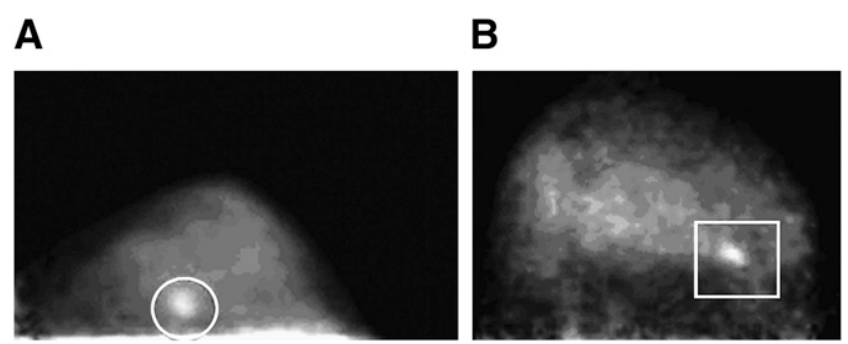

FIGURE 1. Demonstration of small invasive breast cancer using ${ }^{18} \mathrm{~F}-\mathrm{FDG}$ PEM. Images from dedicated breast PEM units show $9-\mathrm{mm}$ (circle in A) and 1.3-cm (rectangle in B) invasive cancer. (Adapted with permission of (40).)

also maintains higher count sensitivity. In addition to compression capability, dedicated devices have a small physical footprint, which makes their use in a breast-imaging facility feasible, allows correlation with mammography, and permits PEM-guided biopsy. Early studies demonstrated that PEM is capable of imaging smaller breast cancers than is ${ }^{18}$ F-FDG PET (40). Moreover, a recent multicenter trial also suggested that PEM may aid in the detection and characterization of both invasive and in situ breast carcinoma (41). Berg et al. reported that 10 of 11 in situ carcinomas were detected by PEM, and 8 of 10 were detected by mammography and ultrasonography (41). The reported limitations for PEM include the imaging of posterior lesions, variable ${ }^{18} \mathrm{~F}-\mathrm{FDG}$ uptake in small tumors, and false-positive findings from prior biopsy $(41,42)$. Recently, PEM with capability of biopsy has been developed and is being tested (43). However, the clinical data regarding dedicated positron breast-imaging devices are still limited, particularly compared with the large amount of data supporting and validating screening mammography and other adjunctive primary breast-imaging modalities such as ultrasound and breast MRI. Although the PEM devices so far can, in part, overcome the limitations of whole-body ${ }^{18} \mathrm{~F}-\mathrm{FDG}$ PET in breast cancer detection, the utility of PEM, compared with existing breast-imaging methods, awaits validation in larger prospective trials before more general acceptance and more widespread clinical use.

\section{Single-Photon Breast Imaging}

${ }^{99 \mathrm{~m}} \mathrm{Tc}$-sestamibi and related compounds have also been tested for primary breast cancer imaging. ${ }^{99 \mathrm{~m}} \mathrm{Tc}$-sestamibi is a cationic compound that is transferred across the cell membrane into the cytoplasm and mitochondria and retained by electrical potentials across membrane (44). ${ }^{99 \mathrm{~m}} \mathrm{Tc}$-sestamibi uptake and retention in breast cancer appears to depend on several factors such as regional blood flow, plasma and mitochondrial membrane potential, angiogenesis, and tissue metabolism (45-47). Several studies have reported ${ }^{99 \mathrm{~m} T c-}$ sestamibi uptake is higher in breast cancers demonstrating more aggressive features, including higher indices of nuclear grade, higher indices of proliferation, greater microvessel 
density, and high tumor blood flow $(46,47)$, but the precise mechanism of increased uptake and the relative importance of these factors are not completely understood.

Since the first large-series study using prone ${ }^{99 m} \mathrm{Tc}-$ sestamibi scintimammography in 1994 (48), many studies investigating the diagnostic accuracy of this method in evaluation of suspected breast cancer have been published. Liberman et al. (49) performed a meta-analysis and reviewed literature published up until 1999 on the diagnostic accuracy of this method. Overall sensitivity was $85 \%$, specificity $87 \%$, positive predictive value $88 \%$, negative predictive value $81 \%$, and accuracy $86 \%$. Most $(80 \%)$ of the studies reported sensitivity and specificity values higher than $80 \%$, with nearly half of them yielding values higher than $90 \%$. Similar results were seen in a large multicenter prospective clinical trial evaluating the efficacy of ${ }^{99 \mathrm{~m} T c-}$ sestamibi scintimammography for the diagnosis of breast cancer. The sensitivity and specificity of this method were estimated at $93 \%$ and $87 \%$, respectively, with an accuracy of $88 \%$ (50). However, concern remains that ${ }^{99 \mathrm{~m}} \mathrm{Tc}$-sestamibi scintimammography has limited ability to detect lesions less than $1 \mathrm{~cm}$, with sensitivity lower than 50\% in some series (51). ${ }^{99 \mathrm{~m} T c-s e s t a m i b i}$ scintimammography also has comparably lower sensitivity for nonpalpable lesions. False-positive uptake in benign breast lesions, inflammation, hematoma, and fat necrosis can also be seen. As a result of these concerns, ${ }^{99 \mathrm{~m}} \mathrm{Tc}$-sestamibi scintimammography with conventional $\boldsymbol{\gamma}$-cameras has not found widespread use for breast cancer detection and diagnosis.

More recently, high-resolution small-field-of-view $\gamma$-cameras specific to breast imaging, sometimes called breast-specific $\gamma$-imaging (BSGI) or molecular breast imaging, have been developed $(52,53)$. Preliminary data using breast-specific $\gamma$-cameras, compared with $\gamma$-camera imaging, for evaluating women with breast lesions before biopsy demonstrated improved resolution of breast cancer, with improved visualization of nonpalpable lesions, lesions smaller than $1 \mathrm{~cm}$, and in situ carcinoma (53). Brem et al. reported that BSGI correctly identified 16 of 18 cancers $(88.9 \%)$ smaller than $1 \mathrm{~cm}$. The authors also found 5 of 6 in situ carcinoma smaller than $1 \mathrm{~cm}$ (53). Another study by the same group demonstrated higher sensitivity in detection of in situ carcinoma for BSGI versus mammography or breast MRI (52). As with PEM, larger trials with comparisons to standard breast imaging will be needed to support more widespread use of BSGI. These trials are ongoing.

\section{STAGING}

\section{Overview}

The extent of spread at presentation is one of the most important prognostic factors for breast cancer patients (14). Staging is also important for recurrent breast cancer. Staging is typically divided into logoregional staging (for regional lymph nodes, especially axillary nodes) and distant or systemic staging (for sites beyond regional lymph nodes). Almost all patients with invasive breast cancer will undergo axillary nodal staging because the presence or absence of spread to axillary lymph nodes is an important consideration for further treatment after surgery (18). For patients with early-stage breast cancer and without evidence of regional nodal spread (stage I or the low end of stage II), systemic staging is not recommended unless there are symptoms (54) because the chance of distant metastases is low and the chance of false-positive findings in staging studies is considerably higher than is the chance of truepositive findings $(55,56)$. For recurrent breast cancer or breast cancer with known metastases, systemic staging is recommended (54). For LABC, especially for patients with advanced axillary nodal disease, the risk of systemic metastases is high enough that systemic staging is often performed as part of the initial evaluation (30).

\section{Locoregional Staging}

Lymphoscintigraphy. The traditional approach to axillary nodal staging was the axillary nodal dissection, in which axillary contents were removed and examined. The morbidity of this process, including a significant incidence of lymphedema, led to the search for a less morbid but equally accurate approach (18). On the basis of work that had been done for melanoma nodal staging (57), the SLN mapping and sampling approach was tested for breast cancer, with good early success (58-60). SLN sampling has emerged as the standard of care for axillary nodal sampling in patients with clinically negative axillae (61). The approach is to identify and sample the nodes that are the first draining nodes (i.e., sentinels in the axillary drainage basin for the breast lesion), yielding a much smaller surgical procedure than full axillary nodal dissection with much less morbidity (18). If sentinel nodes are negative, then the chance of downstream nodal metastases is quite small, and the patient can be spared the full dissection. If the sentinel node shows evidence of metastasis, then an axillary dissection may be needed to determine the extent of axillary spread. The SLN mapping and sampling approach has been thoroughly tested in large clinical trials and shown to be safe and accurate, with patient outcome comparable to that of axillary nodal dissection $(62,63)$.

Some controversies exist regarding the methodology for SLN biopsy $(64,65)$. Typically, a colloidal radiopharmaceutical ${ }^{99 \mathrm{~m}} \mathrm{Tc}$-sulfur colloid in the United States) is injected, and sentinel nodes are identified through imaging (lymphoscintigraphy; Fig. 2), $\gamma$-probes, or both (66). Other, more specific agents have been developed and are undergoing testing (67). Some centers use both radiocolloid and visible blue dye to guide SLN sampling, whereas some centers use one of the methods without the other (18).

Early studies used perilesional injection of radiotracer or blue dye, under the premise that the area surrounding the tumor would be the most representative of lymphatic drainage pathways (68). More recently, studies have shown that intradermal injection over the lesion site or subareolar 


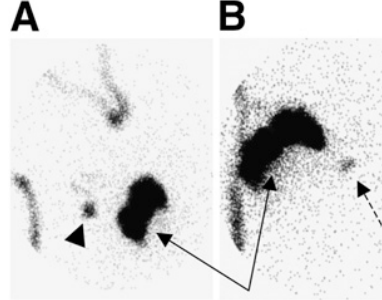

FIGURE 2. Example of lymphoscintigraphy for SLN mapping. Two sets of anterior images are shown, one focused on axilla (A) and other on more central chest (B), taken after perilesional injection of filtered 99mTc-sulfur colloid (solid arrows). Body outline has been indicated using 99mTc markers. Axillary sentinel node is indicated by arrowhead. IM node is also seen (dashed arrow).

injection identifies the same axillary SLN found by perilesional injection (69) and provides similar rates of accuracy for axillary SLN sampling (70). However, most studies done using radiocolloid and lymphoscintigraphy suggest that only perilesional injection provides an accurate depiction of extraaxillary drainage, especially to internal mammary (IM) nodes (68). Studies have shown that approximately 15\%-20\% of lesions that are not in the upper outer quadrant drain to IM lymph nodes after perilesional injection (71).

The importance of sampling IM nodes is a point of considerable debate (72). Some studies using SLN mapping and lymphoscintigraphy to sample IM lymph nodes showed more than $80 \%$ successful sampling of IM nodes when lymphoscintigraphy showed drainage and an approximately $10 \%-20 \%$ positivity rate $(73-75)$. However, routine sampling of IM nodes results in less than a $5 \%$ overall rate of positive IM nodes, and it is rare to have IM lymph node metastasis in the absence of axillary nodal metastases (76).

A

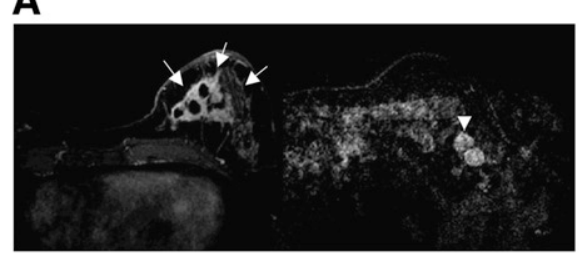

B

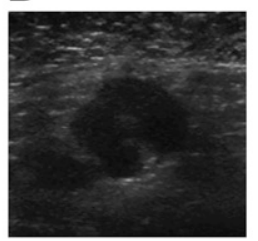

C

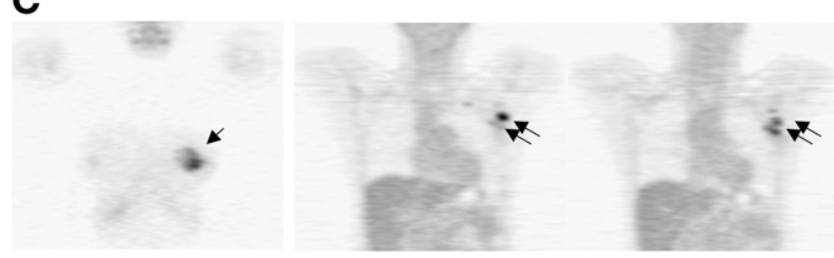

FIGURE 3. Examples of $\angle A B C$ and regional nodal staging $(A-C)$. Contrast-enhanced MRI (A) demonstrates large breast cancer in left breast (arrows) and abnormally enhancing, rounded lymph nodes in the left axilla (arrowhead). Ultrasound (B) shows rounded lymph node with eccentric cortical thickening and deformed fatty hilum in the left axilla, suspected of being metastasis. Coronal PET images (C) reveal ${ }^{18} \mathrm{~F}-\mathrm{FDG}$ uptake in primary tumor (arrow) and axillary lymph nodes (double arrows), confirmed by axillary lymph node biopsy.
As a result, most practices in the United States do not routinely sample IM nodes. With an increasing trend toward intradermal or subareolar injection, spurred by more rapid drainage and a higher success rate (69), along with a trend toward less lymphoscintigraphy because of simplicity and lower expense (18), the sampling of IM nodes using SLN mapping methods is unlikely to be widely used. However, some studies have suggested that knowledge of IM drainage patterns, even without nodal sampling, may provide useful information. Yao et al. (77) found that patients with positive axillary nodes and IM nodal drainage were significantly more likely to relapse and die of breast cancer than those without drainage. Another study found a higher rate of nodal relapse outside the axilla, versus in the axilla, after sentinel node biopsy (78). Such studies prompt careful consideration of the approach to SLN mapping in breast cancer and the potential benefit of perilesional injection and lymphoscintigraphy in selected patients.

${ }^{18}$ F-FDG PET for Axillary Disease. Many early studies of ${ }^{18} \mathrm{~F}-\mathrm{FDG}$ PET for breast cancer were focused on detecting axillary metastases (79). These studies showed sensitivities of largely $85 \%-90 \%$ and higher $(79,80)$, suggesting the feasibility of ${ }^{18}$ F-FDG PET as a noninvasive method for axillary staging and potential substitute for axillary nodal dissection. However, the population of patients in these earlier studies was heavily weighted toward more advanced breast cancer than found in typical screened populations.

More recent studies with a larger fraction of $\mathrm{T} 1$ primary cancers demonstrated lower sensitivities for axillary nodal metastases, as low as $20 \%-30 \%(40)$. These studies also indicated that the sensitivity of ${ }^{18} \mathrm{~F}-\mathrm{FDG}$ PET for axillary nodal metastases depended on both axillary tumor burden and ${ }^{18} \mathrm{~F}$-FDG uptake in the primary tumor. In a prospective multicenter trial representing one of the largest patient cohorts so far $(81),{ }^{18} \mathrm{~F}-\mathrm{FDG}$ PET was performed on 360 women with newly diagnosed invasive breast cancer, and the results were interpreted by 3 experienced readers in a masked manner. The PET results were compared with those of pathologic analysis of axillary nodes. Overall, ${ }^{18} \mathrm{~F}-\mathrm{FDG}$ PET was $61 \%$ sensitive and $80 \%$ specific for axillary metastases, with a positive predictive value of $62 \%$ and a negative predictive value of $79 \%$. Patients who had falsenegative PET results had significantly smaller and fewer tumor-positive lymph nodes than true-positive cases.

These results indicate the limitation of ${ }^{18} \mathrm{~F}-\mathrm{FDG}$ PET in detecting micrometastases and small tumor-infiltrated axillary lymph nodes. Further studies comparing ${ }^{18}$ F-FDG PET with SLN biopsy support SLN biopsy for early-stage disease and confirm the limited sensitivity of ${ }^{18}$ F-FDG PET for axillary nodal metastases in this clinical setting (a sensitivity as low as $20 \%-40 \%$ ), particularly in small (ranging from 1 to $15 \mathrm{~mm}$ ) and isolated lesions $(40,82)$. Thus, ${ }^{18} \mathrm{~F}-\mathrm{FDG}$ PET is not sufficiently accurate to replace SLN biopsy in patients with early-stage breast cancer.

${ }^{18}$ F-FDG PET may, however, have a clinical role for patients with a high likelihood of axillary metastases, such 
A

FIGURE 4. Examples of systemic staging for breast cancer. ${ }^{18} \mathrm{~F}-\mathrm{FDG}$ $\mathrm{PET} / \mathrm{CT}$ demonstrates metastatic disease in left breast extending to chest wall, axillary, supraclavicular, cervical, IM, mediastinal, and hilar nodes (A); areas of abnormal uptake are indicated by arrows. For patient in B, ${ }^{18} \mathrm{~F}-\mathrm{FDG}$ $\mathrm{PET} / \mathrm{CT}$ shows extensive nodal metastases in axillary, mediastinal, cervical, and retroperitoneal locations. In patient with recurrent breast cancer in $\mathrm{C}$, initial contrast-enhanced CT image (top left) revealed pericardial effusion and thickening. Subsequent ${ }^{18} \mathrm{~F}-\mathrm{FDG}$ PET/CT scan (remaining images), obtained without intravenous contrast 3 days later and after pericardiocentesis, shows focal hypermetabolic activity corresponding to pericardial thickening, consistent with pericardial metastases (white arrows and arrowheads). Foci of hypermetabolic activity in both IM and subcarinal lymph nodes (black and blue arrows) are seen, as are bilateral pleural effusions (stars).

C
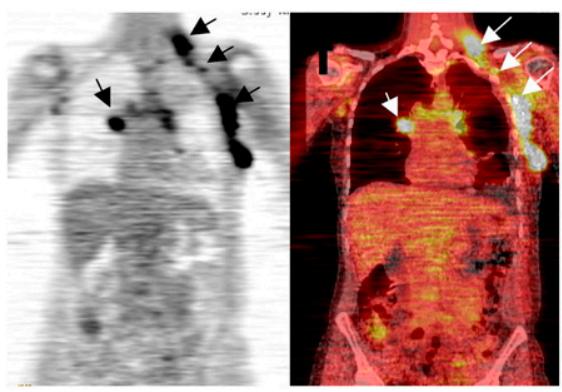

B
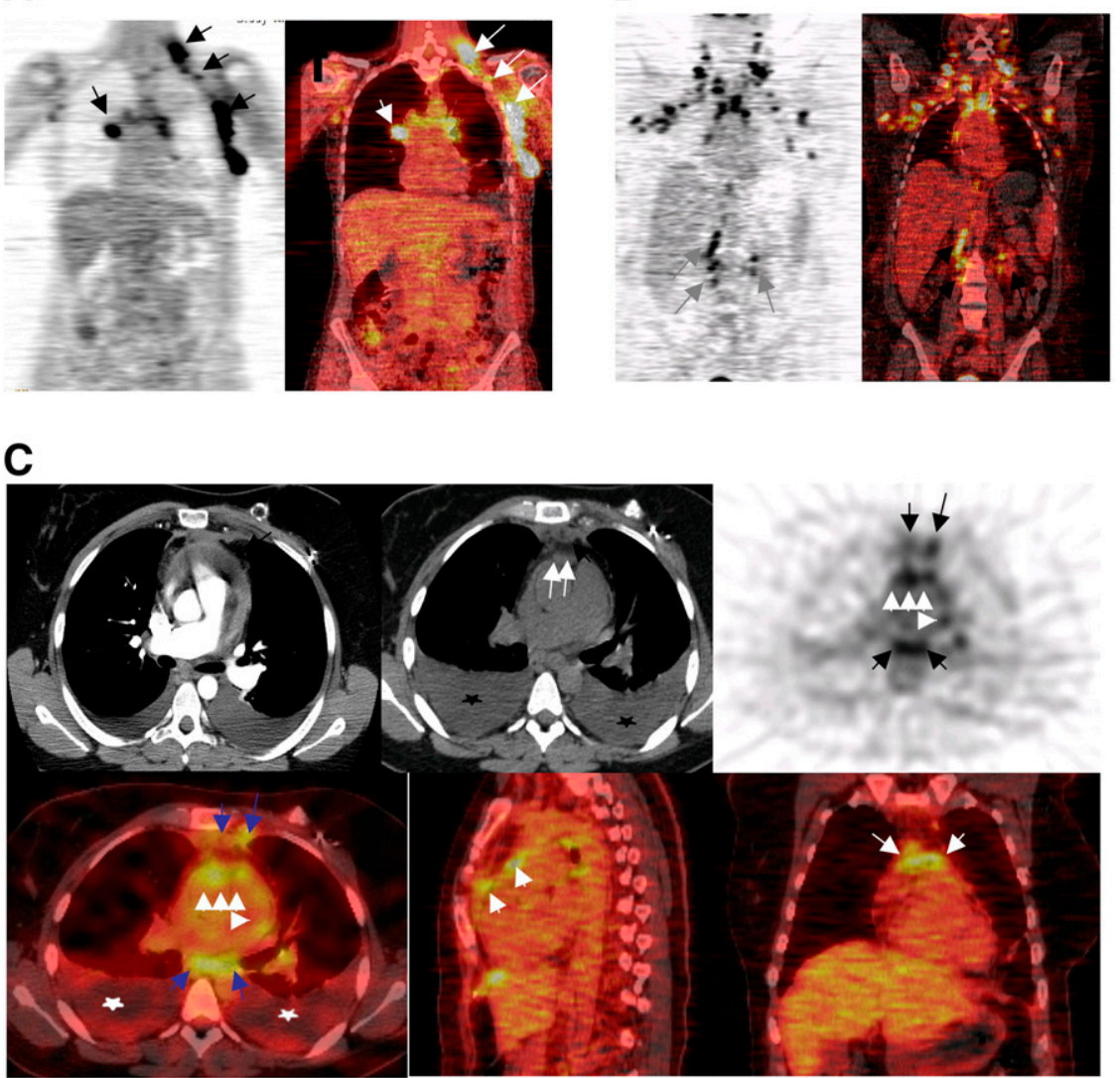

as those patients with locally advanced disease, and for patients with advanced axillary disease, plexopathy, or symptomatic metastases (Fig. 3) (83). Although SLN biopsy is highly sensitive for axillary metastases in early breast cancer and well tolerated by patients, it requires a prolonged surgical session, lymphoscintigraphy, a considerable pathologic work-up, and additional cost. If some of the patients with axillary metastases could be identified before the SLN biopsy, axillary lymph node dissection may be performed directly without SLN biopsy. To identify the patients with axillary metastases, some have suggested the use of ${ }^{18} \mathrm{~F}$-FDG PET, directed ultrasound with ultrasound-guided biopsy, or a combination of both. For ${ }^{18} \mathrm{~F}-\mathrm{FDG}$ PET, most of the studies demonstrate specificities in the range of $93 \%-100 \%$ $(40,84)$. The high specificity of ${ }^{18} \mathrm{~F}-\mathrm{FDG}$ PET could direct the subgroup of patients with axillary disease determined by ${ }^{18}$ F-FDG PET to targeted sampling (e.g., by ultrasound) or to axillary lymph node dissection and avoid the need for SLN biopsy. This approach has been previously suggested and supported by several studies $(65,84-88)$.

Axillary ultrasound and needle biopsy are also helpful and commonly used to identify and sample suspected lymph nodes. Ultrasound features for suspected axillary lymph nodes include asymmetric cortical thickening or lobulations, loss of fatty hilum, abnormal shape (rounded appearance), and increased peripheral flow (89). Ultrasound-guided needle biopsy is simple, relatively easy, minimally invasive, and safe (89). Direct visualization of the tumor cells by fine-needle aspiration and cytology or core-needle biopsy and histology confirms axillary metastatic disease and avoids the need for SLN biopsy for confirmation of axillary nodal disease before definitive axillary treatment. Axillary ultrasound to direct needle biopsy of palpable disease is widely used, and some early studies support the use of ultrasound to screen for metastases in patients at high risk for axillary disease based on primary tumor characteristics $(90,91)$. However, the sensitivity of axillary ultrasound is not as good as that of full nodal sampling and histologic examination; thus, histologic confirmation of a negative axilla by nodal sampling is needed if the ultrasound-guided needle biopsy is negative (91).

Other approaches, including MRI and ultra-small superparamagnetic iron oxide particles, have also been applied to breast cancer axillary nodal staging with promising early results (92), but these approaches are at an early stage of testing. For the immediate future, it appears unlikely that any noninvasive imaging method will provide the same sensitivity as that of SLN biopsy. Thus, SLN biopsy will likely remain the procedure of choice for the staging of axillae, ultrasound the procedure of choice for the sampling of palpable nodes or screening of high-risk axillae, and ${ }^{18} \mathrm{~F}-$ FDG PET an adjunct tool for high-risk patients and for advanced or recurrent axillary disease, possibly in conjunction with MRI (93). 
${ }^{18}$ F-FDG PET for Other Regional Lymph Nodes. ${ }^{18} \mathrm{~F}-$ FDG PET may be helpful in assessing breast cancer spread to regional nodal sites outside the axilla, especially the IM chain. Although IM nodal metastases indicates a higher likelihood of spread or recurrence, these sites are not routinely sampled or evaluated in any systemic fashion in current clinical practice because of their relative inaccessibility and lack of convincing data for improvement in overall survival rate (72). ${ }^{18} \mathrm{~F}-\mathrm{FDG}$ uptake in the IM node has been reported in some of the studies that have focused on detection of primary or axillary staging, showing IM nodal uptake as high as $25 \%$ (94). Moreover, some reports have suggested that IM ${ }^{18} \mathrm{~F}$-FDG uptake predicts treatment failure patterns of disease consistent with IM nodal involvement and progression (95). Tran et al. showed that the likelihood of an extraaxillary lymph node finding on ${ }^{18} \mathrm{~F}-$ FDG PET was affected by the position of the tumor (medial vs. lateral). The presence of extraaxillary nodal uptake on ${ }^{18} \mathrm{~F}-\mathrm{FDG}$ PET, combined with medial tumor location, indicated a high risk of subsequent disease progression (96). A preliminary study by Jones et al. showed the feasibility of detecting IM nodal metastases in early-stage patients using ${ }^{18}$ F-FDG PET (97), although more data are required to further validate the results.

\section{Distant (Systemic) Staging}

Indications and Standard Approach. The presence of distant metastases, outside the breast and regional nodes, is an important factor predicting prognosis and directing the intensity of care, because metastatic (stage IV) breast cancer has a low likelihood of cure. Because of the low yield, cost, and distress associated with investigating detected abnormalities that are-for the most part-falsepositives, baseline systemic staging is neither performed nor recommended (54) before surgery and axillary staging in patients with early-stage breast cancer $(56,98,99)$. In the patients with more advanced disease (such as LABC or inflammatory breast cancer), however, some evidence supports the use of systemic imaging staging at the diagnosis to rule out stage IV disease, which would significantly alter treatment options because of the high likelihood of distant metastases $(30,100)$. Baseline systemic imaging staging needs to survey the chest, abdomen, pelvis, and bones and includes chest radiography or CT, abdominal ultrasound or $\mathrm{CT}$, and bone scintigraphy. According to current National Comprehensive Cancer Network Practice guidelines (54), only chest radiography is recommended for stage I disease, and additional bone scintigraphy may be considered for node-positive stage II disease. However, chest radiography or CT and liver ultrasound or CT may be optionally included for stage II disease with positive lymph nodes and a high index of suspicion. A combination of these standard systemic imaging modalities (typically abdominal CT, bone scanning, and possible chest and pelvis CT) are indicated for stage III disease or higher. ${ }^{18} \mathrm{~F}$-FDG PET or $\mathrm{PET} / \mathrm{CT}$ is recommended as an option for patients with either recurrent or stage IV disease in earlier breast guidelines and recent PET-specific guidelines (101).

Bone Scintigraphy and Fluoride PET. Bone is the most common site for breast cancer metastasis, and bone metastases will develop in $30 \%-85 \%$ of patients with metastatic breast cancer during the course of disease $(102,103)$. Bone also represents the first site of metastasis for $26 \%-50 \%$ of patients with metastatic breast carcinoma $(103,104)$. Bone metastases in breast cancer can be osteoblastic (bone formation), osteolytic (bone resorption), or mixed lesions. Up to half of all bone metastases from breast cancer tend to show osteolytic changes. Breast cancer preferentially metastasizes to the spine and pelvis, followed by ribs, skull, and femur (103).

Whole-body bone scintigraphy, namely bone scanning, is the most commonly used method of detecting bone metastases (103). This method shows an increase in osteoblastic activity and vascularity $(103,105)$. The most commonly used radiopharmaceutical is ${ }^{99 \mathrm{~m}} \mathrm{Tc}$-methylene diphosphonate or -hydroxymethylene diphosphonate. The reported sensitivity ranges from $62 \%$ to $100 \%$, and specificity ranges from $78 \%$ to $100 \%(103,106)$. Although a bone scan is generally considered sensitive for detecting bone metastases at reasonable cost, it has low specificity and high falsepositive rates because several other diseases such as trauma, degenerative change, or inflammation can mimic bone metastases. False-negative results can occur in the presence of predominantly osteolytic metastases, low bone turnover, or avascular regions (such as necrosis) (103). Anatomic imaging modalities such as $\mathrm{CT}$ and MRI provide correlative imaging. CT is particularly useful in evaluating the risk of fracture when the index of suspicion is high. MRI and ${ }^{18} \mathrm{~F}-$ FDG PET are useful in evaluating predominantly osteolytic lesions $(107,108)$.

Another way to improve the specificity of bone scanning is to perform additional SPECT studies (109). SPECT is particularly helpful in characterizing solitary lesions in the spine or in differentiating bone metastases from degenerative lesions. For example, if radiotracer uptake is seen in the middle or posterior part of the vertebral body, then the lesion is likely a metastasis rather than a degenerative lesion. Savelli et al. reported the sensitivity and specificity of SPECT to be over 90\%, similar to that of MRI studies, although MRI can effectively visualize predominantly lytic lesions as well as blastic lesions (109).

Some studies have examined the use of fluoride $\left({ }^{18} \mathrm{~F}^{-}\right)$ PET for bone metastases detection and have shown ${ }^{18} \mathrm{~F}^{-}$ PET to be superior to bone scanning and SPECT in detecting metastases and differentiating malignant from benign lesions (110-112). The mechanism of localization of fluoride in bone and uptake in bone metastases is similar to that of diphosphonates in that both are deposited in newly mineralizing bone accompanying osteoblastic activity (108). ${ }^{18} \mathrm{~F}^{-}$, compared with ${ }^{99 \mathrm{~m}} \mathrm{Tc}$-labeled conventional bone-scanning agents, has higher bone uptake and faster blood clearance and, combined with the favorable imaging 
performance of PET, results in a superior target-to-background ratio (108). ${ }^{18} \mathrm{~F}^{-}$PET and PET/CT have been shown to be more accurate than bone scanning for the detection of both osteolytic and osteoblastic lesions in various malignancies including breast cancer and have been suggested as an alternative to bone scanning, mainly in patients at high risk for metastatic bone disease $(110,111)$. Schirrmeister et al. found more metastatic lesions on ${ }^{18} \mathrm{~F}^{-}$ PET, compared with bone scanning with additional SPECT, resulting in a change in clinical management in $12 \%$ of patients (110). Subsequent prospective studies also demonstrated similar results, although the study population was the group of patients with lung cancer bone metastases. Schirrmeister et al. reported that bone scanning identified 5 of 12 patients, bone scanning with SPECT identified 10 patients, and ${ }^{18} \mathrm{~F}^{-}$PET identified 12 patients (113). A larger-scale study by Hetzel et al. also demonstrated bone scanning and SPECT identified 29 of 33 patients with bone metastases found by spine MRI, and ${ }^{18} \mathrm{~F}^{-}$PET found 31 of 33 patients (114). The authors also found that bone scanning and SPECT, compared with ${ }^{18} \mathrm{~F}^{-}$PET, underestimated the extent of disease in 16 patients. Even-Sapir et al. showed further improved sensitivity for ${ }^{18} \mathrm{~F}^{-}$PET/CT versus PET (111). Although recent studies have successfully shown that ${ }^{18} \mathrm{~F}^{-}$PET has higher diagnostic accuracy in the assessment of bone metastases, longstanding familiarity with bone scanning, concerns for the cost of ${ }^{18} \mathrm{~F}^{-}$ PET, and a lack of data on the clinical impact of improved diagnostic accuracy of ${ }^{18} \mathrm{~F}^{-}$PET, compared with bone scanning, have somewhat limited the use of ${ }^{18} \mathrm{~F}^{-}$PET, but its use can be expected to increase with more experience and data.

${ }^{18}$ F-FDG PET and PET/CT. The reported sensitivities and specificities of ${ }^{18} \mathrm{~F}$-FDG PET for the detection of distant metastases range from $80 \%$ to $100 \%$ and from $50 \%$ to $97 \%$, respectively (115).

In one of the earliest studies of ${ }^{18} \mathrm{~F}$-FDG PET for staging of systemic breast cancer, Moon et al. evaluated ${ }^{18} \mathrm{~F}-\mathrm{FDG}$ PET performed in 57 patients with suspected recurrent or metastatic breast cancer and demonstrated that this modality was $93 \%$ sensitive and $79 \%$ specific (116). ${ }^{18} \mathrm{~F}-\mathrm{FDG}$ PET, compared with conventional imaging modalities, was also reported to be more sensitive; Mahner et al. showed that ${ }^{18} \mathrm{~F}$-FDG PET was $87 \%$ sensitive and $83 \%$ specific, whereas combined conventional imaging modalities were $43 \%$ sensitive and $98 \%$ specific (117). Thus, ${ }^{18}$ F-FDG PET detected more metastatic lesions than did other imaging modalities including CT and could be helpful by detecting occult metastases that were not otherwise detected in conventional imaging modalities, affecting and changing therapeutic options (Fig. 4).

The additional sensitivity of ${ }^{18}$ F-FDG PET/CT for regional nodes and distant disease may be particularly important in staging for LABC. LABC (including a primary tumor larger than $5 \mathrm{~cm}$; skin or chest wall involvement; fixed axillary nodes; positive supraclavicular, infraclavicu- lar, or IM nodes; and inflammatory cancer) has a poor prognosis because of the high incidence of distant metastases during follow-up (118). Currently, the standard approach is neoadjuvant chemotherapy followed by surgery with axillary nodal dissection and radiation. However, some patients with apparent LABC may have occult distant metastases, in which case aggressive therapies with curative intent may not be indicated. Thus, detecting distant metastases in the patients with LABC is crucial for determining treatment. Evidence supports the utility of ${ }^{18} \mathrm{~F}$-FDG PET in LABC at diagnosis. Several studies showed detection rates of confirmed metastatic disease in LABC at diagnosis ranging from $8 \%$ to $14 \%(119-121)$. ${ }^{18} \mathrm{~F}-\mathrm{FDG}$ PET is particularly helpful in detecting IM and mediastinal nodal metastases $(95,122)$. These are common sites for metastatic involvement in LABC and are not optimally evaluated with conventional imaging alone. ${ }^{18}$ F-FDG PET and PET/CT can improve staging and alter therapeutic options in patients with LABC and locoregional recurrence.

${ }^{18}$ F-FDG PET and PET/CT are helpful in the detection of skeletal metastases but have an important difference from bone scanning and fluoride imaging. Several studies demonstrated that ${ }^{18} \mathrm{~F}$-FDG PET is superior to bone scanning in the detection of lytic and intramedullary metastases but inferior in the detection of primarily osteoblastic lesions. Cook et al. showed that ${ }^{18}$ F-FDG PET detected lytic metastases often missed by bone scanning, whereas ${ }^{18} \mathrm{~F}$ FDG PET often missed osteoblastic metastases, for which bone scanning is superior (107). Subsequent studies confirmed these findings $(40,108)$. Therefore, ${ }^{18} \mathrm{~F}-\mathrm{FDG}$ PET complements bone scanning. In standard clinical practice, the combination of bone scanning and $\mathrm{CT}$ remains the standard imaging modality when staging is clinically indicated, and ${ }^{18}$ F-FDG PET and PET/CT are particularly helpful in clarifying difficult or equivocal cases. Ongoing studies will continue to clarify the best use of ${ }^{18} \mathrm{~F}-\mathrm{FDG}$ PET/CT for staging of systemic breast cancer.

\section{CONCLUSION}

Breast cancer is a common disorder in women and a leading cause of death. Imaging plays an important role in the detection, diagnosis, staging, and response evaluation of breast cancer. Radiotracer imaging methods play an important current role in breast cancer staging and response evaluation, including SLN mapping, bone scintigraphy, and ${ }^{18}$ F-FDG PET/CT. Ongoing trials of dedicated devices for primary tumor imaging using breast-dedicated PET and SPECT may lead to increased use for primary tumor diagnosis and determination of the extent of disease in the breast; however, more studies are needed. Radionuclide imaging plays an important role in axillary staging through its contribution to SLN mapping. Noninvasive methods for axillary nodal detection such as ${ }^{18}$ F-FDG PET/CT appear to be relatively insensitive for early-stage disease but can play an important role in determining the extent of nodal 
involvement for more advanced breast cancer, especially LABC. Radionuclide imaging plays an important role in distant metastasis staging for breast cancer patients with locally advanced, recurrent, or metastatic disease. Part 2 of this review will highlight the application of radionuclide imaging to breast cancer response evaluation and targeted breast cancer therapy.

\section{ACKNOWLEDGMENTS}

We acknowledge the help of Erin Schubert, Lisa Dunnwald, and Lanell Peterson with capturing the images used in the figures and the support of the molecular imaging and breast cancer groups at the University of Washington and Seattle Cancer Care Alliance. This work was supported in part by National Institutes of Health grants CA42045, CA72064, CA90771, and CA124573.

\section{REFERENCES}

1. Jemal A, Siegel R, Ward E, Murray T, Xu J, Thun MJ. Cancer statistics, 2007. CA Cancer J Clin. 2007;57:43-66.

2. Clarke M. Meta-analyses of adjuvant therapies for women with early breast cancer: the Early Breast Cancer Trialists' Collaborative Group overview. Ann Oncol. 2006;17(suppl 10):x59-x62.

3. Slamon DJ, Leyland-Jones B, Shak S, et al. Use of chemotherapy plus a monoclonal antibody against HER2 for metastatic breast cancer that overexpresses HER2. N Engl J Med. 2001;344:783-792.

4. Doyle DM, Miller KD. Development of new targeted therapies for breast cancer. Breast Cancer. 2008;15:49-56.

5. Lefferts JA, Bartels CL, Tsongalis GJ. Molecular oncology: current trends in diagnostics. Future Oncol. 2008;4:61-70.

6. Mankoff DA.Molecular imaging as a tool for translating breast cancer basic science. Breast Cancer Res. 2008;10(suppl 1):S3. Available at: breast-cancerresearch.com/content/10/S1/S3. Accessed March 4, 2009.

7. Salehi F, Turner MC, Phillips KP, Wigle DT, Krewski D, Aronson KJ. Review of the etiology of breast cancer with special attention to organochlorines as potential endocrine disruptors. J Toxicol Environ Health. 2008;11:276-300.

8. King MC, Marks JH, Mandell JB, New York Breast Cancer Study Group. Breast and ovarian cancer risks due to inherited mutations in BRCA1 and BRCA2. Science. 2003;302:643-646.

9. Schnitt SJ. Traditional and newer pathologic factors. J Natl Cancer Inst Monogr. 2001;2001:22-26.

10. Walker RA. Immunohistochemical markers as predictive tools for breast cancer. J Clin Pathol. 2008;61:689-696.

11. Symmans WF. A pathologist's perspective on emerging genomic tests for breast cancer. Semin Oncol. 2007;34(2, suppl 3):S4-S9.

12. Rakha EA, Reis-Filho JS, Ellis IO. Basal-like breast cancer: a critical review. J Clin Oncol. 2008;26:2568-2581.

13. Ross JS, Hatzis C, Symmans WF, Pusztai L, Hortobagyi GN. Commercialized multigene predictors of clinical outcome for breast cancer. Oncologist. 2008;13:477-493.

14. Singletary SE, Connolly JL. Breast cancer staging: working with the sixth edition of the AJCC Cancer Staging Manual. CA Cancer J Clin. 2006;56:3747.

15. Vazquez B, Rousseau D, Hurd TC. Surgical management of breast cancer. Semin Oncol. 2007;34:234-240.

16. Fisher B. From Halsted to prevention and beyond: advances in the management of breast cancer during the twentieth century. Eur J Cancer. 1999;35:19631973.

17. Chen CY, Calhoun KE, Masetti R, Anderson BO. Oncoplastic breast conserving surgery: a renaissance of anatomically-based surgical technique. Minerva Chir. 2006;61:421-434.

18. Newman EA, Newman LA. Lymphatic mapping techniques and sentinel lymph node biopsy in breast cancer. Surg Clin North Am. 2007;87:353-364.

19. Gervasoni JE Jr, Sbayi S, Cady B. Role of lymphadenectomy in surgical treatment of solid tumors: an update on the clinical data. Ann Surg Oncol. 2007; 14:2443-2462.
20. Bellon JR, Katz A, Taghian A. Radiation therapy for breast cancer. Hematol Oncol Clin North Am. 2006;20:239-257.

21. Chen PY, Vicini FA. Partial breast irradiation: patient selection, guidelines for treatment, and current results. Front Radiat Ther Oncol. 2007;40:253-271.

22. Ragaz J, Jackson SM, Le N, et al. Adjuvant radiotherapy and chemotherapy in node-positive premenopausal women with breast cancer. $N$ Engl J Med. 1997;337:956-962.

23. Carlson RW, Brown E, Burstein HJ, et al. NCCN Task Force report: adjuvant therapy for breast cancer. J Natl Compr Canc Netw. 2006;4(suppl 1):S1-S26.

24. Come SE, Buzdar AU, Ingle JN, et al. Endocrine and targeted manipulation of breast cancer: summary statement for the Sixth Cambridge Conference. Cancer. 2008;112(3, suppl):673-678.

25. Gralow JR. Optimizing the treatment of metastatic breast cancer. Breast Cancer Res Treat. 2005;89(suppl 1):S9-S15.

26. Moasser MM. Targeting the function of the HER 2 oncogene in human cancer therapeutics. Oncogene. 2007;26:6577-6592.

27. Miller K, Wang M, Gralow J, et al. Paclitaxel plus bevacizumab versus paclitaxel alone for metastatic breast cancer. N Engl J Med. 2007;357:26662676.

28. Cleator S, Heller W, Coombes RC. Triple-negative breast cancer: therapeutic options. Lancet Oncol. 2007;8:235-244.

29. Estevez LG, Martin M, Alba E, et al. Current controversies in the management of early breast cancer. Clin Transl Oncol. 2007;9:375-384.

30. Chia S, Swain SM, Byrd DR, Mankoff DA. Locally advanced and inflammatory breast cancer. J Clin Oncol. 2008;26:786-790.

31. Scheidhauer K, Walter C, Seemann MD. FDG PET and other imaging modalities in the primary diagnosis of suspicious breast lesions. Eur $\mathrm{J} \mathrm{Nucl}$ Med Mol Imaging. 2004;31(suppl 1):S70-S79.

32. Elmore JG, Armstrong K, Lehman CD, Fletcher SW. Screening for breast cancer. JAMA. 2005;293:1245-1256.

33. Stavros AT, Thickman D, Rapp CL, Dennis MA, Parker SH, Sisney GA. Solid breast nodules: use of sonography to distinguish between benign and malignant lesions. Radiology. 1995;196:123-134.

34. Lehman CD, Schnall MD. Imaging in breast cancer: magnetic resonance imaging. Breast Cancer Res. 2005;7:215-219.

35. Mendelson EB. Problem-solving ultrasound. Radiol Clin North Am. 2004; 42:909-918

36. Saslow D, Boetes C, Burke W, et al. American Cancer Society guidelines for breast screening with MRI as an adjunct to mammography. CA Cancer J Clin. 2007;57:75-89.

37. Avril N, Menzel M, Dose J, et al. Glucose metabolism of breast cancer assessed by ${ }^{18}$ F-FDG PET: histologic and immunohistochemical tissue analysis. $\mathrm{J} \mathrm{Nucl}$ Med. 2001;42:9-16.

38. Bos R, van Der Hoeven JJ, van Der Wall E, et al. Biologic correlates of ${ }^{18}$ fluorodeoxyglucose uptake in human breast cancer measured by positron emission tomography. J Clin Oncol. 2002;20:379-387.

39. Kumar R, Chauhan A, Zhuang H, Chandra P, Schnall M. Clinicopathologic factors associated with false negative FDG-PET in primary breast cancer. Breast Cancer Res Treat. 2006;98:267-274.

40. Rosen EL, Eubank WB, Mankoff DA. FDG PET, PET/CT, and breast cancer imaging. Radiographics. 2007;27(suppl 1):S215-S229.

41. Berg WA, Weinberg IN, Narayanan D, et al. High-resolution fluorodeoxyglucose positron emission tomography with compression ("positron emission mammography") is highly accurate in depicting primary breast cancer. Breast J. 2006;12:309-323.

42. Rosen EL, Turkington TG, Soo MS, Baker JA, Coleman RE. Detection of primary breast carcinoma with a dedicated, large-field-of-view FDG PET mammography device: initial experience. Radiology. 2005;234:527-534.

43. Raylman RR, Majewski S, Smith MF, et al. The positron emission mammography/tomography breast imaging and biopsy system (PEM/PET): design, construction and phantom-based measurements. Phys Med Biol. 2008;53:637653.

44. Chiu ML, Kronauge JF, Piwnica-Worms D. Effect of mitochondrial and plasma membrane potentials on accumulation of hexakis (2-methoxyisobutylisonitrile) technetium(I) in cultured mouse fibroblasts. J Nucl Med. 1990;31:1646-1653.

45. Buscombe JR, Cwikla JB, Thakrar DS, Hilson AJ. Uptake of Tc-99m MIBI related to tumour size and type. Anticancer Res. 1997;17:1693-1694.

46. Mankoff DA, Dunnwald LK, Gralow JR, et al. [Tc-99m]-sestamibi uptake and washout in locally advanced breast cancer are correlated with tumor blood flow. Nucl Med Biol. 2002;29:719-727.

47. Scopinaro F, Schillaci O, Scarpini M, et al. Technetium-99m sestamibi: an indicator of breast cancer invasiveness. Eur J Nucl Med. 1994;21:984-987.

48. Khalkhali I, Mena I, Jouanne E, et al. Prone scintimammography in patients with suspicion of carcinoma of the breast. J Am Coll Surg. 1994;178:491-497. 
49. Liberman M, Sampalis F, Mulder DS, Sampalis JS. Breast cancer diagnosis by scintimammography: a meta-analysis and review of the literature. Breast Cancer Res Treat. 2003;80:115-126.

50. Sampalis FS, Denis R, Picard D, et al. International prospective evaluation of scintimammography with ${ }^{99 m}$ technetium sestamibi. Am J Surg. 2003;185:544549.

51. Waxman $\mathrm{AD}$. The role of ${ }^{99 \mathrm{~m}} \mathrm{Tc}$ methoxyisobutylisonitrile in imaging breast cancer. Semin Nucl Med. 1997;27:40-54

52. Brem RF, Fishman M, Rapelyea JA. Detection of ductal carcinoma in situ with mammography, breast specific gamma imaging, and magnetic resonance imaging: a comparative study. Acad Radiol. 2007;14:945-950.

53. Brem RF, Floerke AC, Rapelyea JA, Teal C, Kelly T, Mathur V. Breast-specific gamma imaging as an adjunct imaging modality for the diagnosis of breast cancer. Radiology. 2008;247:651-657.

54. Carlson RW, Anderson BO, Burstein HJ, et al. Invasive breast cancer. J Natl Compr Canc Netw. 2007;5:246-312.

55. Norum J, Andreassen T. Screening for metastatic disease in newly diagnosed breast cancer patients: what is cost-effective? Anticancer Res. 2000;20:2193-2196.

56. Puglisi F, Follador A, Minisini AM, et al. Baseline staging tests after a new diagnosis of breast cancer: further evidence of their limited indications. Ann Oncol. 2005;16:263-266.

57. Morton DL, Wen DR, Wong JH, et al. Technical details of intraoperative lymphatic mapping for early stage melanoma. Arch Surg. 1992;127:392-399.

58. Albertini JJ, Lyman GH, Cox C, et al. Lymphatic mapping and sentinel node biopsy in the patient with breast cancer. JAMA. 1996;276:1818-1822.

59. Giuliano AE, Kirgan DM, Guenther JM, Morton DL. Lymphatic mapping and sentinel lymphadenectomy for breast cancer. Ann Surg. 1994;220:391-398.

60. Krag DN, Weaver DL, Alex JC, Fairbank JT. Surgical resection and radiolocalization of the sentinel lymph node in breast cancer using a gamma probe. Surg Oncol. 1993;2:335-339.

61. Lyman GH, Giuliano AE, Somerfield MR, et al. American Society of Clinical Oncology guideline recommendations for sentinel lymph node biopsy in earlystage breast cancer. J Clin Oncol. 2005;23:7703-7720.

62. Langer I, Guller U, Berclaz G, et al. Morbidity of sentinel lymph node biopsy (SLN) alone versus SLN and completion axillary lymph node dissection after breast cancer surgery: a prospective Swiss multicenter study on 659 patients. Ann Surg. 2007;245:452-461.

63. Vanderveen KA, Schneider PD, Khatri VP, Goodnight JE, Bold RJ. Upstaging and improved survival of early breast cancer patients after implementation of sentinel node biopsy for axillary staging. Ann Surg Oncol. 2006;13:1450-1456.

64. Motomura K, Egawa C, Komoike Y, et al. Sentinel node biopsy for breast cancer: technical aspects and controversies. Breast Cancer. 2007;14:25-30.

65. Veronesi P, Rodriguez-Fernandez J, Intra M. Controversies in the use of sentinel nodes: microinvasion, post surgery and after preoperative systemic treatment. Breast. 2007;16(suppl 2):S67-S70.

66. Aarsvold JN, Alazraki NP. Update on detection of sentinel lymph nodes in patients with breast cancer. Semin Nucl Med. 2005;35:116-128.

67. Wallace AM, Hoh CK, Ellner SJ, Darrah DD, Schulteis G, Vera DR. Lymphoseek: a molecular imaging agent for melanoma sentinel lymph node mapping. Ann Surg Oncol. 2007;14:913-921.

68. Nieweg OE. Lymphatics of the breast and the rationale for different injection techniques. Ann Surg Oncol. 2001;8(9, suppl):71S-73S.

69. Paganelli G, De Cicco C, Cremonesi $\mathrm{M}$, et al. Optimized sentinel node scintigraphy in breast cancer. $Q$ J Nucl Med. 1998;42:49-53.

70. Mudun A, Sanli Y, Ozmen V, et al. Comparison of different injection sites of radionuclide for sentinel lymph node detection in breast cancer: single institution experience. Clin Nucl Med. 2008;33:262-267.

71. Byrd DR, Dunnwald LK, Mankoff DA, et al. Internal mammary lymph node drainage patterns in patients with breast cancer documented by breast lymphoscintigraphy. Ann Surg Oncol. 2001;8:234-240.

72. Sugg SL, Ferguson DJ, Posner MC, Heimann R. Should internal mammary nodes be sampled in the sentinel lymph node era? Ann Surg Oncol. 2000; 7:188-192.

73. Estourgie SH, Nieweg OE, Olmos RA, Rutgers EJ, Kroon BB. Lymphatic drainage patterns from the breast. Ann Surg. 2004;239:232-237.

74. Farrus B, Vidal-Sicart S, Velasco M, et al. Incidence of internal mammary node metastases after a sentinel lymph node technique in breast cancer and its implication in the radiotherapy plan. Int $J$ Radiat Oncol Biol Phys. 2004;60:715-721.

75. Paganelli G, Galimberti V, Trifiro G, et al. Internal mammary node lymphoscintigraphy and biopsy in breast cancer. Q J Nucl Med. 2002;46:138-144.

76. van Rijk MC, Tanis PJ, Nieweg OE, et al. Clinical implications of sentinel nodes outside the axilla and internal mammary chain in patients with breast cancer. J Surg Oncol. 2006;94:281-286.
77. Yao MS, Kurland BF, Smith AH, et al. Internal mammary nodal chain drainage is a prognostic indicator in axillary node-positive breast cancer. Ann Surg Oncol. 2007; 14:2985-2993.

78. van der Ploeg IM, Kroon BB, Antonini N, Valdes Olmos RA, Rutgers EJ, Nieweg OE. Axillary and extra-axillary lymph node recurrences after a tumornegative sentinel node biopsy for breast cancer using intralesional tracer administration. Ann Surg Oncol. 2008;15:1025-1031.

79. Crippa F, Gerali A, Alessi A, Agresti R, Bombardieri E. FDG-PET for axillary lymph node staging in primary breast cancer. Eur J Nucl Med Mol Imaging. 2004;31(suppl 1):S97-S102.

80. Eubank W, Mankoff D. Current and future uses of positron emission tomography in breast cancer imaging. Semin Nucl Med. 2004;34:224-240.

81. Wahl RL, Siegel BA, Coleman RE, Gatsonis CG. Prospective multicenter study of axillary nodal staging by positron emission tomography in breast cancer: a report of the staging breast cancer with PET Study Group. J Clin Oncol. 2004;22:277-285.

82. Powles T, Murray I, Brock C, Oliver T, Avril N. Molecular positron emission tomography and PET/CT imaging in urological malignancies. Eur Urol. 2007;51:1511-1520.

83. Eubank WB, Mankoff DA. Evolving role of positron emission tomography in breast cancer imaging. Semin Nucl Med. 2005;35:84-99.

84. Eubank WB, Mankoff DA. Current and future uses of positron emission tomography in breast cancer imaging. Semin Nucl Med. 2004;34:224-240.

85. Gil-Rendo A, Zornoza G, Garcia-Velloso MJ, Regueira FM, Beorlegui C, Cervera M. Fluorodeoxyglucose positron emission tomography with sentinel lymph node biopsy for evaluation of axillary involvement in breast cancer. $\mathrm{Br} \mathrm{J}$ Surg. 2006;93:707-712.

86. Kumar R, Zhuang H, Schnall M, et al. FDG PET positive lymph nodes are highly predictive of metastasis in breast cancer. Nucl Med Commun. 2006; 27:231-236.

87. Lovrics PJ, Chen V, Coates G, et al. A prospective evaluation of positron emission tomography scanning, sentinel lymph node biopsy, and standard axillary dissection for axillary staging in patients with early stage breast cancer. Ann Surg Oncol. 2004;11:846-853.

88. Zornoza G, Garcia-Velloso MJ, Sola J, Regueira FM, Pina L, Beorlegui C. ${ }^{18} \mathrm{~F}-\mathrm{FDG}$ PET complemented with sentinel lymph node biopsy in the detection of axillary involvement in breast cancer. Eur J Surg Oncol. 2004;30:15-19.

89. Abe H, Schmidt RA, Sennett CA, Shimauchi A, Newstead GM. US-guided core needle biopsy of axillary lymph nodes in patients with breast cancer: why and how to do it. Radiographics. 2007;27(suppl 1):S91-S99.

90. Ciatto S, Brancato B, Risso G, et al. Accuracy of fine needle aspiration cytology (FNAC) of axillary lymph nodes as a triage test in breast cancer staging. Breast Cancer Res Treat. 2007;103:85-91.

91. Davis JT, Brill YM, Simmons S, et al. Ultrasound-guided fine-needle aspiration of clinically negative lymph nodes versus sentinel node mapping in patients at high risk for axillary metastasis. Ann Surg Oncol. 2006;13:1545-1552.

92. Memarsadeghi M, Riedl CC, Kaneider A, et al. Axillary lymph node metastases in patients with breast carcinomas: assessment with nonenhanced versus USPIO-enhanced MR imaging. Radiology. 2006;241:367-377.

93. Hathaway PB, Mankoff DA, Maravilla KR, et al. The value of combined FDGPET and magnetic resonance imaging in the evaluation of suspected recurrent local-regional breast cancer: preliminary experience. Radiology. 1999;210: 807-814.

94. Danforth DN Jr, Aloj L, Carrasquillo JA, et al. The role of ${ }^{18} \mathrm{~F}-\mathrm{FDG}$-PET in the local/regional evaluation of women with breast cancer. Breast Cancer Res Treat. 2002;75:135-146.

95. Bellon JR, Livingston RB, Eubank WB, et al. Evaluation of the internal mammary lymph nodes by FDG-PET in locally advanced breast cancer (LABC). Am J Clin Oncol. 2004;27:407-410.

96. Tran A, Pio BS, Khatibi B, Czernin J, Phelps ME, Silverman DH. ${ }^{18}$ F-FDG PET for staging breast cancer in patients with inner-quadrant versus outerquadrant tumors: comparison with long-term clinical outcome. J Nucl Med. 2005;46:1455-1459.

97. Jones A, Bernstein V, Davis N, Bryce C, Wilson D, Mankoff D. Pilot feasibility study to assess the utility of PET scanning in the pre-operative evaluation of internal mammary nodes in breast cancer patients presenting with medial hemisphere tumors [abstract]. Clin Positron Imaging. 1999;2:331.

98. Ravaioli A, Pasini G, Polselli A, et al. Staging of breast cancer: new recommended standard procedure. Breast Cancer Res Treat. 2002;72:53-60.

99. Hodgson NC, Gulenchyn KY. Is there a role for positron emission tomography in breast cancer staging? J Clin Oncol. 2008;26:712-720.

100. Shenkier T, Weir L, Levine M, Olivotto I, Whelan T, Reyno L. Clinical practice guidelines for the care and treatment of breast cancer: 15 . Treatment for women with stage III or locally advanced breast cancer. CMAJ. 2004;170:983-994. 
101. Podoloff DA, Advani RH, Allred C, et al. NCCN task force report: positron emission tomography (PET)/computed tomography (CT) scanning in cancer. J Natl Compr Canc Netw. 2007;5(suppl 1):S1-S22.

102. Hortobagyi GN. Bone metastases in breast cancer patients. Semin Oncol. 1991;18(4, suppl 5):11-15.

103. Hamaoka T, Madewell JE, Podoloff DA, Hortobagyi GN, Ueno NT. Bone imaging in metastatic breast cancer. J Clin Oncol. 2004;22:2942-2953.

104. Pivot X, Asmar L, Hortobagyi GN, Theriault R, Pastorini F, Buzdar A. A retrospective study of first indicators of breast cancer recurrence. Oncology. 2000;58:185-190.

105. Rybak LD, Rosenthal DI. Radiological imaging for the diagnosis of bone metastases. Q J Nucl Med. 2001;45:53-64.

106. Crippa F, Seregni E, Agresti R, Bombardieri E, Buraggi GL. Bone scintigraphy in breast cancer: a ten-year follow-up study. J Nucl Biol Med. 1993;37:57-61.

107. Cook GJ, Houston S, Rubens R, Maisey MN, Fogelman I. Detection of bone metastases in breast cancer by ${ }^{18}$ FDG PET: differing metabolic activity in osteoblastic and osteolytic lesions. J Clin Oncol. 1998;16:3375-3379.

108. Fogelman I, Cook G, Israel O, Van der Wall H. Positron emission tomography and bone metastases. Semin Nucl Med. 2005;35:135-142.

109. Savelli G, Maffioli L, Maccauro M, De Deckere E, Bombardieri E. Bone scintigraphy and the added value of SPECT (single photon emission tomography) in detecting skeletal lesions. Q J Nucl Med. 2001;45:27-37.

110. Schirrmeister H, Guhlmann A, Kotzerke J, et al. Early detection and accurate description of extent of metastatic bone disease in breast cancer with fluoride ion and positron emission tomography. J Clin Oncol. 1999;17:2381-2389.

111. Even-Sapir E, Metser U, Flusser G, et al. Assessment of malignant skeletal disease: initial experience with F18-fluoride PET/CT and comparison between ${ }^{18}$ F-fluoride PET and ${ }^{18}$ F-fluoride PET/CT. J Nucl Med. 2004;45:272-278.

112. Grant FD, Fahey FH, Packard AB, Davis RT, Alavi A, Treves ST. Skeletal PET with ${ }^{18}$ F-fluoride: applying new technology to an old tracer. J Nucl Med. 2008;49:68-78.
113. Schirrmeister H, Glatting G, Hetzel J, et al. Prospective evaluation of the clinical value of planar bone scans, SPECT, and ${ }^{18} \mathrm{~F}$-labeled NaF PET in newly diagnosed lung cancer. J Nucl Med. 2001;42:1800-1804.

114. Hetzel M, Arslandemir C, Konig HH, et al. F-18 NaF PET for detection of bone metastases in lung cancer: accuracy, cost-effectiveness, and impact on patient management. J Bone Miner Res. 2003;18:2206-2214.

115. Eubank WB. Diagnosis of recurrent and metastatic disease using F-18 fluorodeoxyglucose-positron emission tomography in breast cancer. Radiol Clin North Am. 2007;45:659-667.

116. Moon DH, Maddahi J, Silverman DH, Glaspy JA, Phelps ME, Hoh CK. Accuracy of whole-body fluorine-18-FDG PET for the detection of recurrent or metastatic breast carcinoma. J Nucl Med. 1998;39:431-435.

117. Mahner S, Schirrmacher S, Brenner W, et al. Comparison between positron emission tomography using 2-[fluorine-18]fluoro-2-deoxy-D-glucose, conventional imaging and computed tomography for staging of breast cancer. Ann Oncol. 2008;19:1249-1254.

118. Perez EA, Foo ML, Fulmer JT. Management of locally advanced breast cancer. Oncology (Williston Park, N.Y.). 1997;11(9 suppl 9):9-17.

119. Baslaim MM, Bakheet SM, Bakheet R, Ezzat A, El-Foudeh M, Tulbah A. 18Fluorodeoxyglucose-positron emission tomography in inflammatory breast cancer. World J Surg. 2003;27:1099-1104.

120. Landheer ML, Steffens MG, Klinkenbijl JH, Westenberg AH, Oyen WJ. Value of fluorodeoxyglucose positron emission tomography in women with breast cancer. Br J Surg. 2005;92:1363-1367.

121. van der Hoeven JJ, Krak NC, Hoekstra OS, et al. ${ }^{18} \mathrm{~F}-2$-fluoro-2-deoxy-Dglucose positron emission tomography in staging of locally advanced breast cancer. J Clin Oncol. 2004;22:1253-1259.

122. Eubank WB, Mankoff DA, Takasugi J, et al. ${ }^{18}$ Fluorodeoxyglucose positron emission tomography to detect mediastinal or internal mammary metastases in breast cancer. J Clin Oncol. 2001;19:3516-3523. 